\title{
LAYANAN BANTUAN TEKNIS DAN BAKTI SOSIAL DI DUSUN SILIRKROMBANG DESA SENEPOREJO KECAMATAN SILIRAGUNG KABUPATEN BANYUWANGI JAWA TIMUR
}

\author{
I.N. Susanta ${ }^{1}$, N.M. Swanendri ${ }^{2}$, G.A.M. Suartika ${ }^{3}$, I.W. Yudamanik ${ }^{4}$, I.N. Sutarja ${ }^{5}$
}

\begin{abstract}
ABSTRAK
Pura Wonorejo terletak di Dusun Silirkrombang Desa Senepoorejo Kecamatan Silir Agung Kabupaten Banyuwangi, Jawa Timur. Pura ini merupakan sebuah pura yang oleh pengemongnya disebut juga dengan Pura Puja Dewata. Saat ini, walau secara umum kondisi fisik pura dapat dikatakan baik, namun dalam beberapa hal masih memerlukan penataan. Kondisi demikian telah mendorong pihak pengepong, pengurus dan pemangku untuk melakukan kegiatan penataan. Kegiatan penataan itu sendiri diawali dengan perencanaan yang telah dibuat dan atas punia dari Universitas Udayana melalui kegiatan pengabdian 'Hibah Udayana Mengabdi 2016'. Bertolak dari kondisi tersebut, pengemong mengajukan inisiatif kembali untuk melaksanakan perbaikan/ pembangunan pada areal Pura Puja Dewata, yang mana dalam pelaksanaannya memerlukan bantuan teknis pembangunan berupa bimbingan dan pengawasan agar penataan dapat berjalan lancer, sesuai dengan tatanan filosofis, ettika dan upakara serta sesuai dengan desain rencana yang telah dibuat. Kegiatan layanan bantuan teknis bimbingan dan pengawasan pembangunan dirangkaikan juga dengan kegiatan bakti sosial untuk mensinergikan antara kegiatan tim layanan bantuan teknis dengan aktivitas sosial masyarakat setempat melalui Hibah Pengabdian Institusi periode 2017.
\end{abstract}

Kata kunci : Layanan, bantuan, bakti, sosial

\begin{abstract}
Pura Wonorejo is located in Silirkrombang Village, Senepoorejo Village, Silir Agung Sub-district, Banyuwangi District, East Java. This temple is a temple which by pengemong also called Pura Puja Dewata. Currently, although in general the physical condition of the temple can be said good, but in some cases still require structuring. Such conditions have encouraged the pemepong, administrators and stakeholders to conduct the arrangement activities. The arrangement activity itself begins with the planning that has been made and the punia of Udayana University through the activities of devotion 'Grant Udayana Mengabdi 2016'. Based on these conditions, the pengemong proposed a re-initiative to carry out the improvement / development in the area of Pura Puja Dewata, which in its implementation requires technical development assistance in the form of guidance and supervision so that the arrangement can run smoothly, in accordance with the philosophical order and upakara and in accordance with the design plans that have been made. The activities of technical guidance and supervisory development services are coupled with social service activities to synergize the activities of the technical assistance team with local community social activities through Institutional Devotion Grants for the period of 2017.
\end{abstract}

Keywords : Service, help, devotion, social

\footnotetext{
${ }^{1}$ Dosen Program Studi Arsitektur, Fakultas Teknik Universitas Udayana, susanta@unud.ac.id

${ }^{2}$ Dosen Program Studi Arsitektur, Fakultas Teknik Universitas Udayana, swanendri@unud.ac.id

${ }^{3}$ Dosen Program Studi Arsitektur, Fakultas Teknik Universitas Udayana, suartika@unud.ac.id

${ }^{4}$ Dosen Program Studi Arsitektur, Fakultas Teknik Universitas Udayana, windu@.unud.ac.id

${ }^{5}$ Dosen Program Studi Arsitektur, Fakultas Teknik Universitas Udayana, sutarja@unud.ac.id
} 


\section{PENDAHULUAN}

Pura Wonorejo terletak di Dusun Silirkrombang Desa Senepoorejo Kecamatan Silir Agung Kabupaten Banyuwangi, Jawa Timur. Pura ini disebut juga dengan nama Pura Puja Dewata. sebagai stana Ida Sang Hyang Widhi Wasa. Pura ini satu-satunya tempat sembahyang bagi umat Hindu di dusun Silirkrombang Desa Seneporejo dan desa di wilayah sekitarnya yang belum memiliki pura. Pengemong pura berjumlah sekitar $150 \mathrm{KK}$. Pura juga berperan sebagai wadah aktivitas social seni budaya. Di Pura ini persembahyangan dilaksanakan setiap hari, pada hari-hari tertentu seperti keliwon, purnama, tilem, hari perayaan seperti saraswati, galungan, kuningan, siwalatri, nyepi serta hari piodalan.

Area Pura Puja Dewa luasnya $305 \mathrm{M}^{2}$, suasana lingkungan pura terletak di pinggir permukiman yang hetrogen dan dominan dikelilingi oleh kebun. Hulu pura ada di timur, pintu masuk ada di posisi barat. Pada jeroan pura terdapat beberapa bangunan antara lain : Padmasana, Taksu, Anglurah, dan Pawedan. Dikelilingi oleh penyengker setinggi 1,6 M. Pada sisi barat terdapat Kori di bagian tengah dan candi bentar dua buah di kiri kanannya.

Dalam kontek keagamaan Hindu rasa bakti wajib ditujukan kepada catur guru yaitu 1) Guru Swadyaya yaitu Ida Sang Hyang Widhi; leluhur yang terdiri dari 2) Guru Rupaka pendahulu yang mengadakan keturunan; 3) Guru Pengajian para pengajar weda seperti para rsi dan para yogi; 4) Guru Wisesa selaku penguasa/ pemerintah, para raja, para tetua desa. Guru yang paling mendasar wajib distanakan yaitu Guru Swadaya dan leluhur, sebagaimana konsep umum pembangunan pura di Jawa.

Penataan pura yang komprehensif sesuai dengan filosofi dan kaidah-kaidah rancang bangun, dilengkapi dengan Pelinggih gedong yang difungsikan sebagai stana leluhur. Rencana penataaan telah menghasilkan gambar desain sudah diselesaikan melalui kegiatan Hibah Udayana Mengabdi pada tahun 2016.

Bertolak dari kondisi tersebut, pengemong mengajukan inisiatif untuk melakukan perbaikan/ pembangunan pada areal Pura Puja Dewata, yang mana dalam pelaksanaannya memerlukan bantuan teknis pembangunan berupa bimbingan dan pengawasan agar penataan dapat berjalan lancar dan sesuai dengan desain rencana yang telah dibuat. Kegiatan layanan bantuan teknis bimbingan dan pengawasan pembangunan dirangkaikan juga dengan kegiatan bakti social untuk mensinergikan antara kegiatan layanan bantuan teknis dan aktivitas social masyarakat setempat melalui Pengabdian Institusi Universitas Udayana periode 2017. Inisiatif ini mendapat dukungan penuh dari Universitas Udayana khususnya Jurusan Arsitektur Fakultas Teknik yang selama ini memang secara kontinyu memberikan dukungan teknis bagi penataan bangunan pura yang berada di wilayah sekitar Banyuwangi. sebagai salah satu perwujudan Tri Dharma Perguruan Tinggi.

\section{METODE PEMECAHAN MASALAH}

Secara keseluruhan, teknis pelaksanaan meliputi: Studi Literatur, Focus Group Discussion /Diskusi, Observasi Lapangan, Analisis dan sintesis. Pada tahap eksekusi, dilakukan pengawasan dan bimbingan teknis secara langsung ke lokasi pembangunan secara berkala. Pada saat ini lansung memberikan arahan dan petunjuk kepada tukang, mandor dan masyarakat pengempon bersinergi dalam wujud bakti sosial serta gotong royong.

\section{HASIL DAN PEMBAHASAN}

Terdapat beberapa tahapan pelaksanaan penataaan pengabdian ini dituangkan dalam dokumen foto antara lain: 

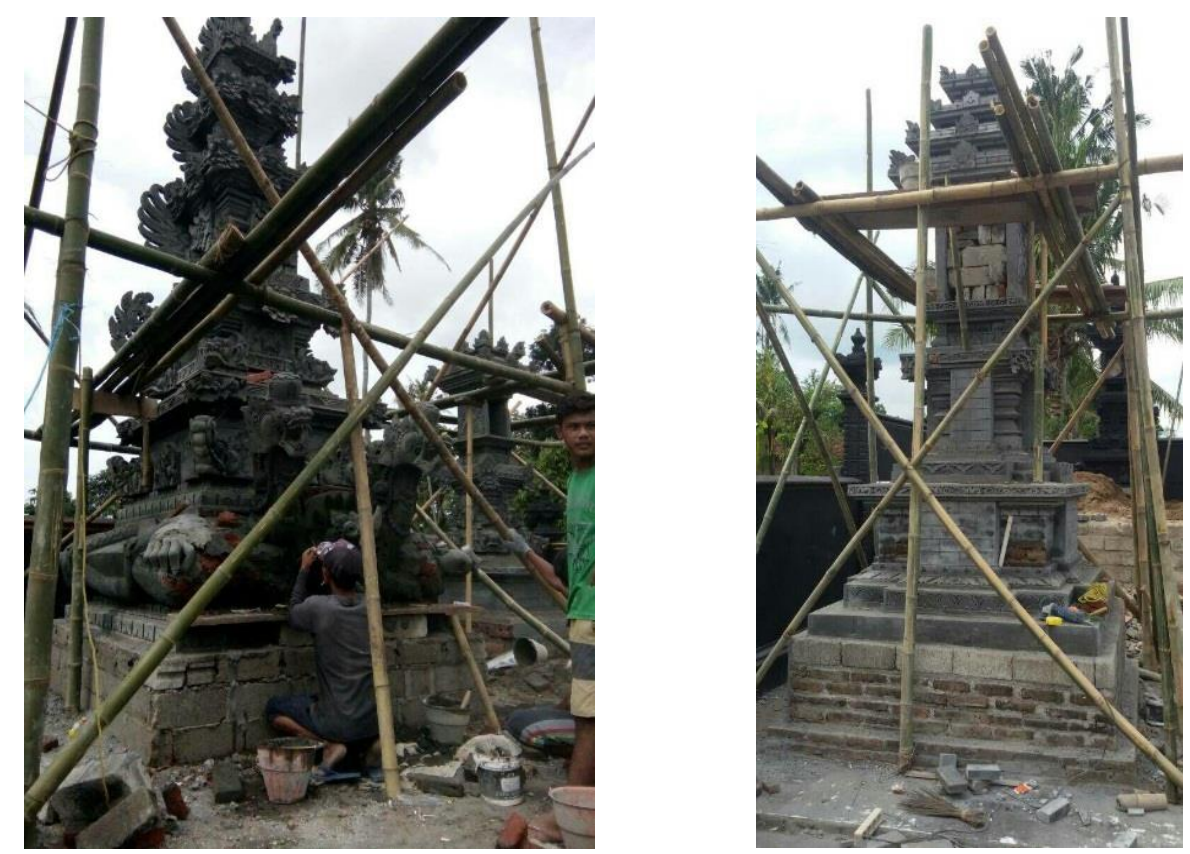

Gambar 1. Pengerjaan Palinggih Padmasana dan Gedong Anglurah Pura Puja Dewata

Di Dusun Silirkrombang Desa Seneporejo Kecamatan Siliragung Kabupaten Banyuwangi Jawa Timur (Sumber: Observasi, Agustus 2017)
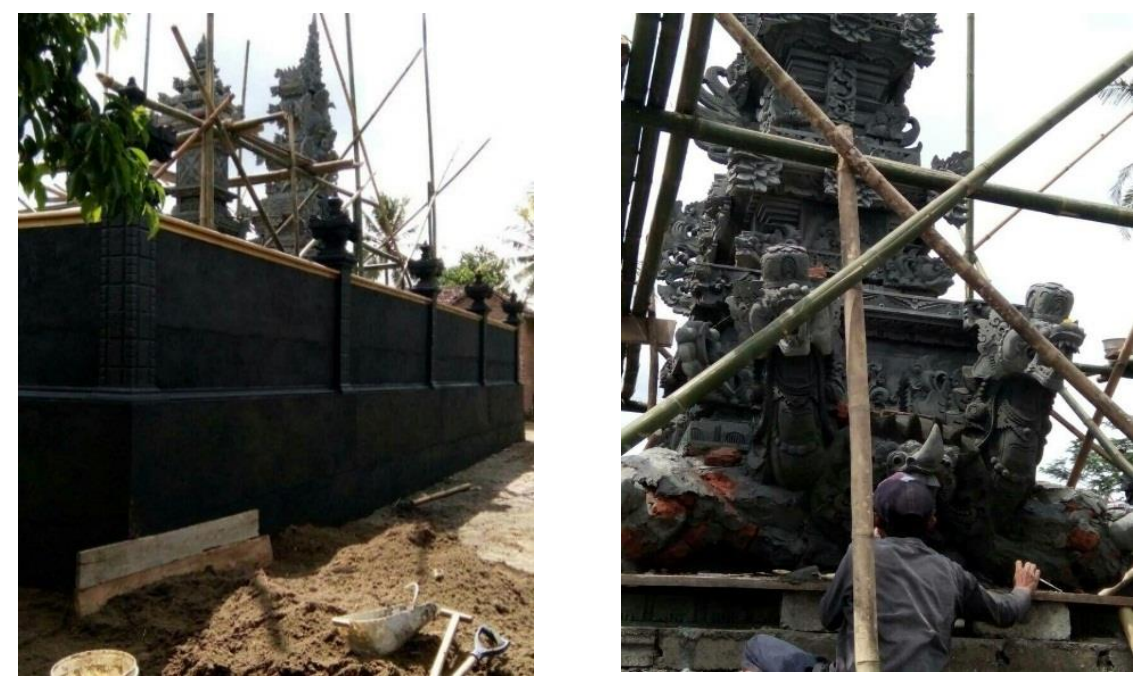

Gambar 2. Pengerjaan Finishing Padmasana Pura Puja Dewata

Di Dusun Silirkrombang Desa Seneporejo Kecamatan Siliragung Kabupaten Banyuwangi Jawa Timur (Sumber: Observasi, Agustus 2017) 

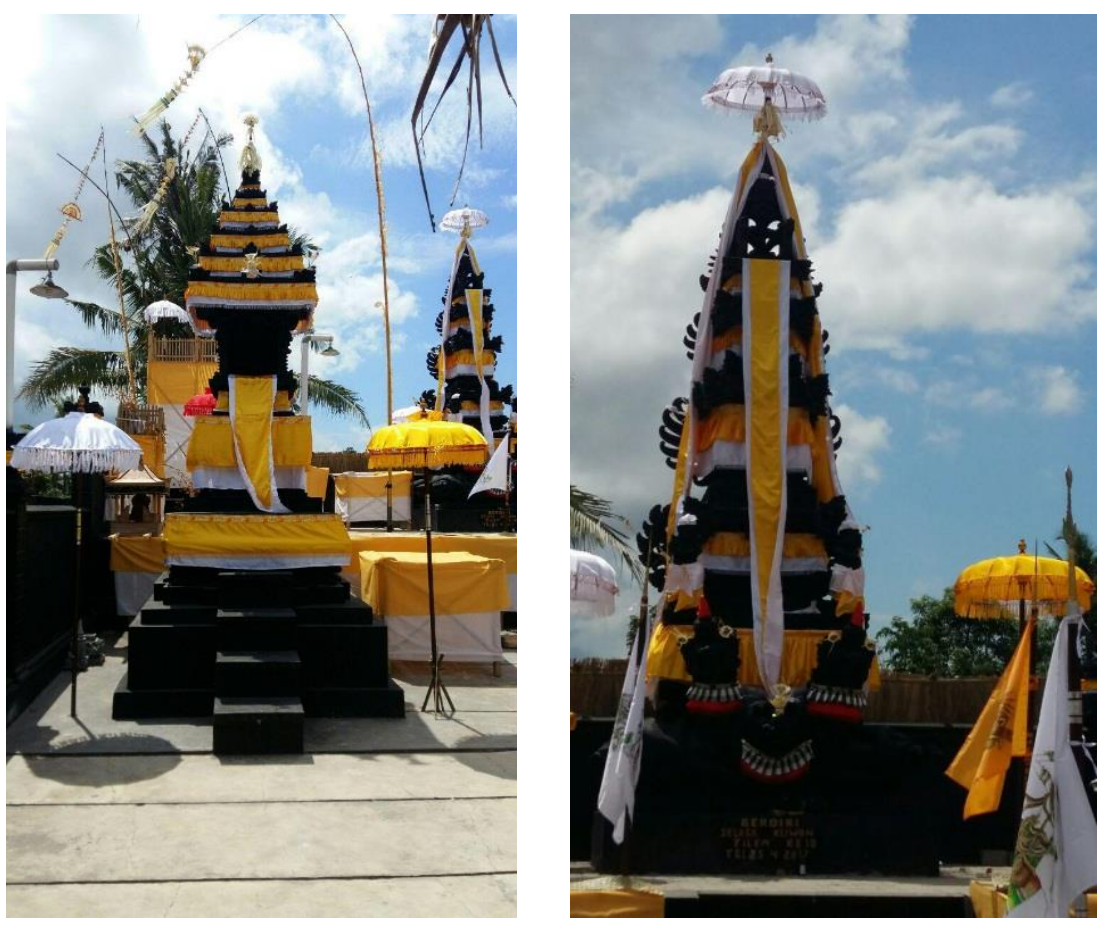

Gambar 3. Bakti Sosial Mempersiapkan Wastra Palinggih Gedong Ibu dan Padmasana Pura Puja Dewata Di Dusun Silirkrombang Desa Seneporejo Kecamatan Siliragung Kabupaten Banyuwangi Jawa Timur (Sumber: Observasi, Oktober 2017)
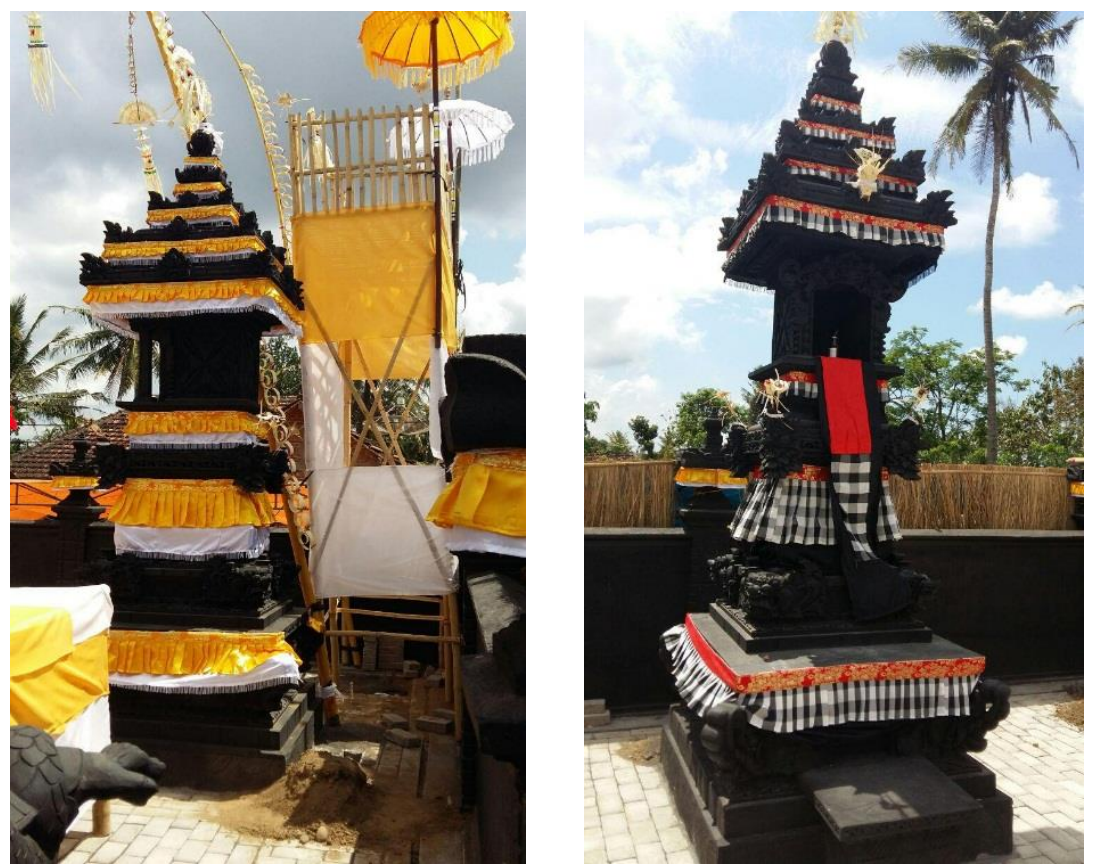

Gambar 4. Bakti Sosial Memasang Wastra Palinggih Taksu dan Anlurah Pura Puja Dewata Di Dusun Silirkrombang Desa Seneporejo Kecamatan Siliragung Kabupaten Banyuwangi Jawa Timur (Sumber: Observasi, Oktober 2017) 
Layanan Bantuan Teknis dan Bakti Sosial Di Dusun Silirkrombang Desa Seneporejo Kecamatan Siliragung Kabupaten Banyuwangi Jawa Timur
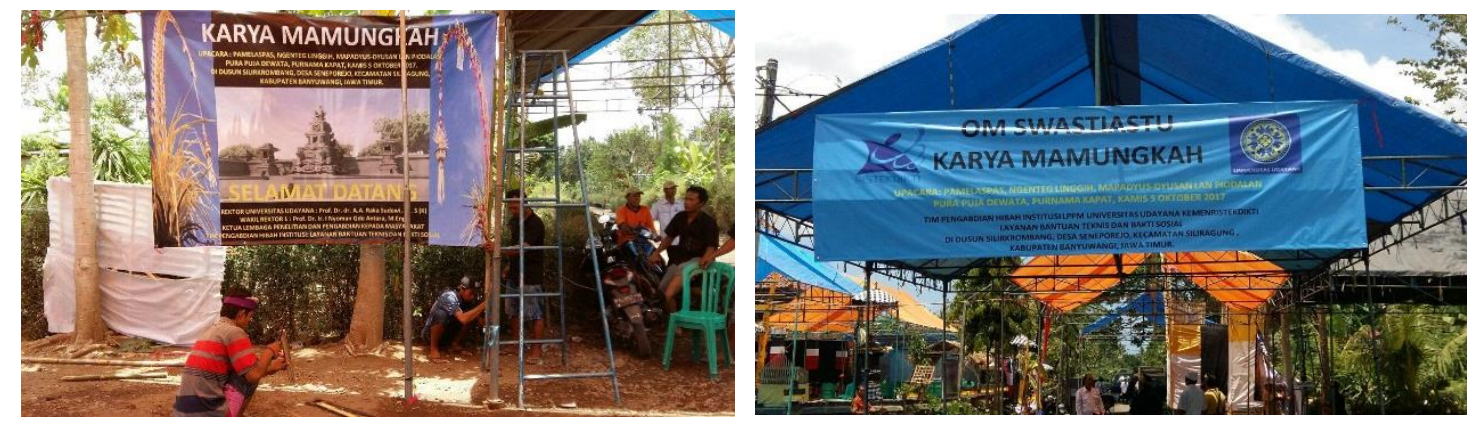

Gambar 4. Bakti Sosial Pemasangan Tribun, Spanduk di Pura Puja Dewata Di

Dusun Silirkrombang Desa Seneporejo Kecamatan Siliragung Kabupaten Banyuwangi Jawa Timur (Sumber: Observasi, Oktober 2017)
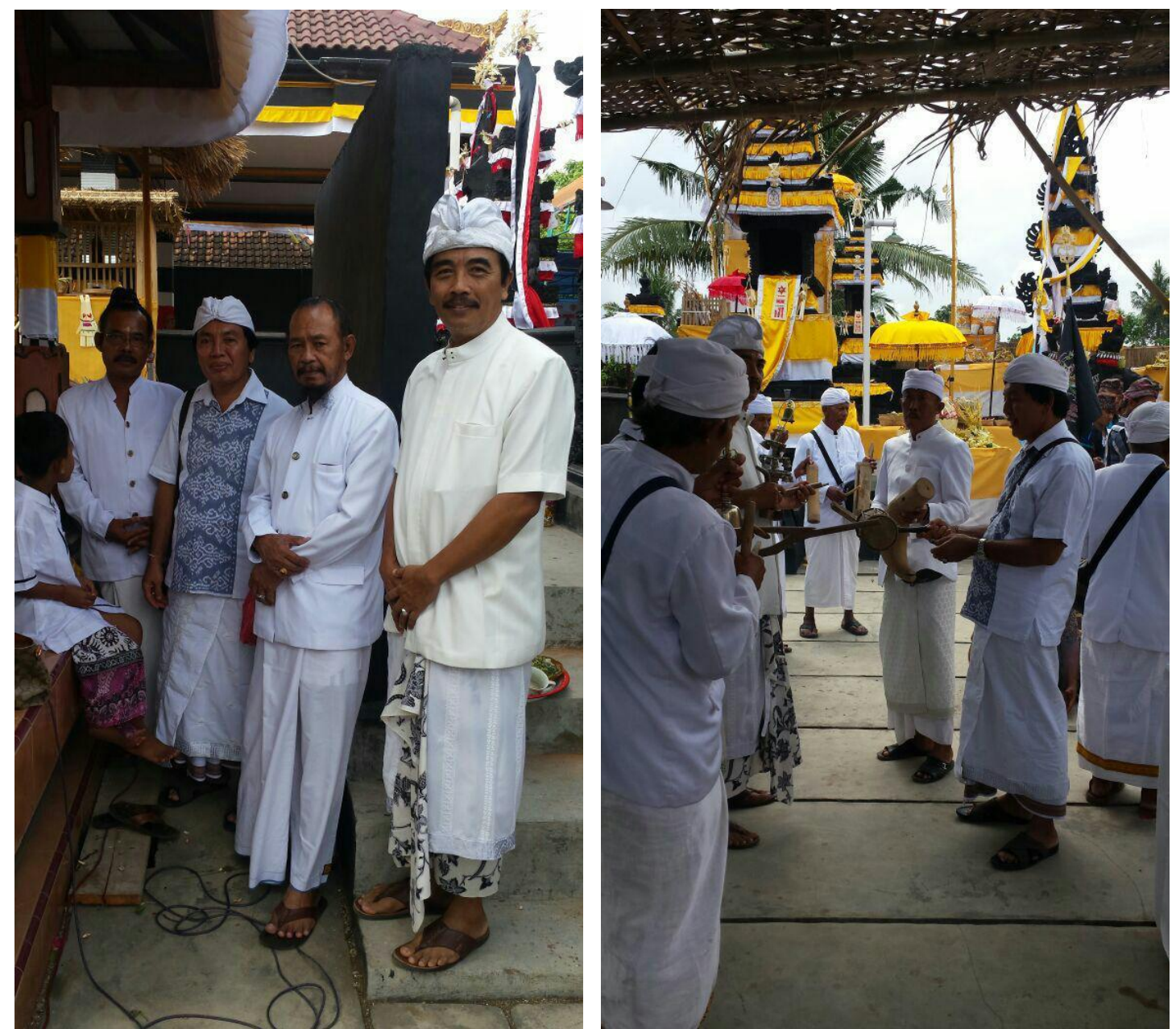

Gambar 5. Perwakilan Rektor Ikut Nyanggra Sulinggih dan Ikut Prosesi Upacara Pamelaspas Pura Puja Dewata Di Dusun Silirkrombang Desa Seneporejo Kecamatan Siliragung Kabupaten Banyuwangi Jawa Timur (Sumber: Observasi, Oktober 2017) 

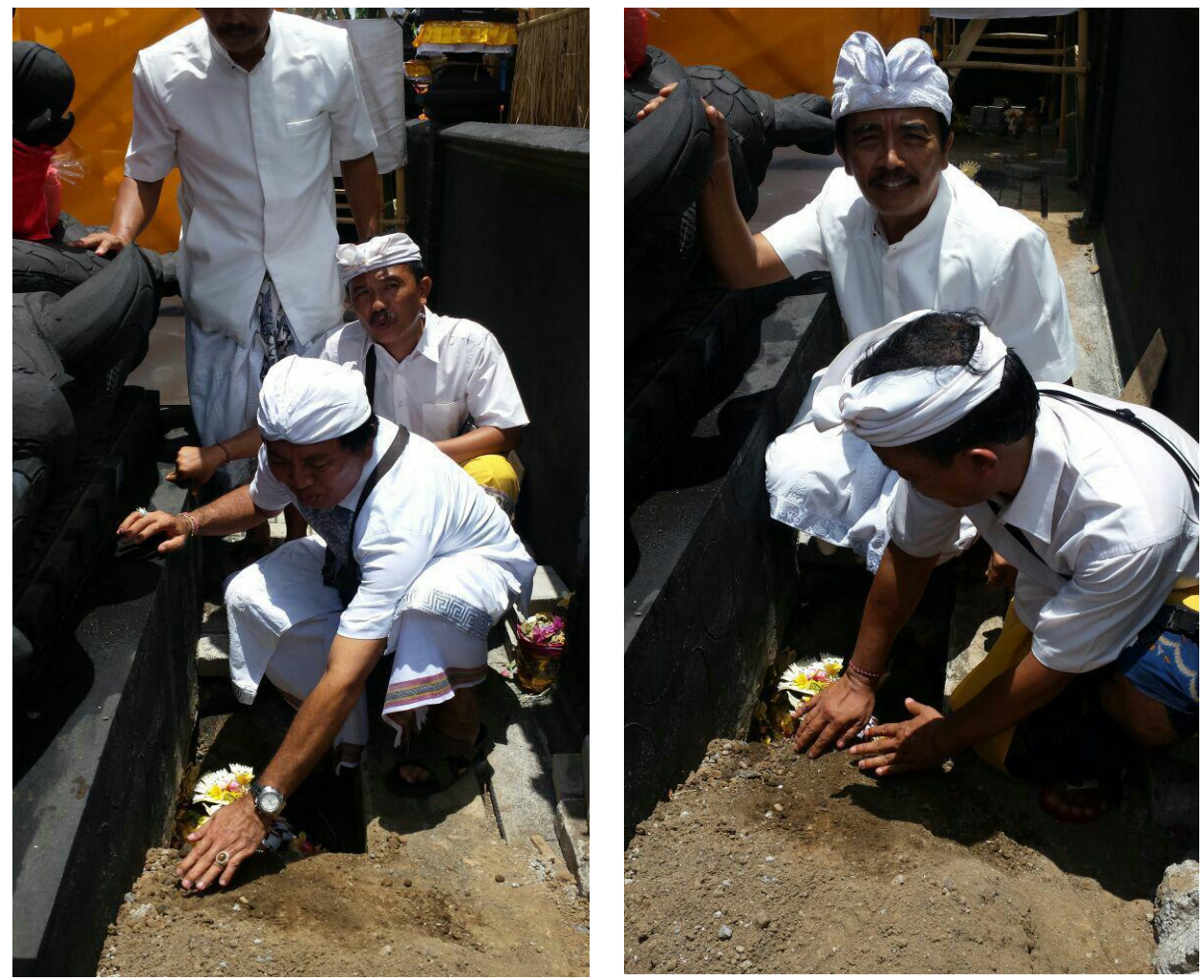

Gambar 6. Bakti Sosial Ikut Ngaturang Ayah Mendem Pedagingan Pura Puja Dewata Di Dusun Silirkrombang Desa Seneporejo Kecamatan Siliragung Kabupaten Banyuwangi Jawa Timur (Sumber: Observasi, Oktober 2017)

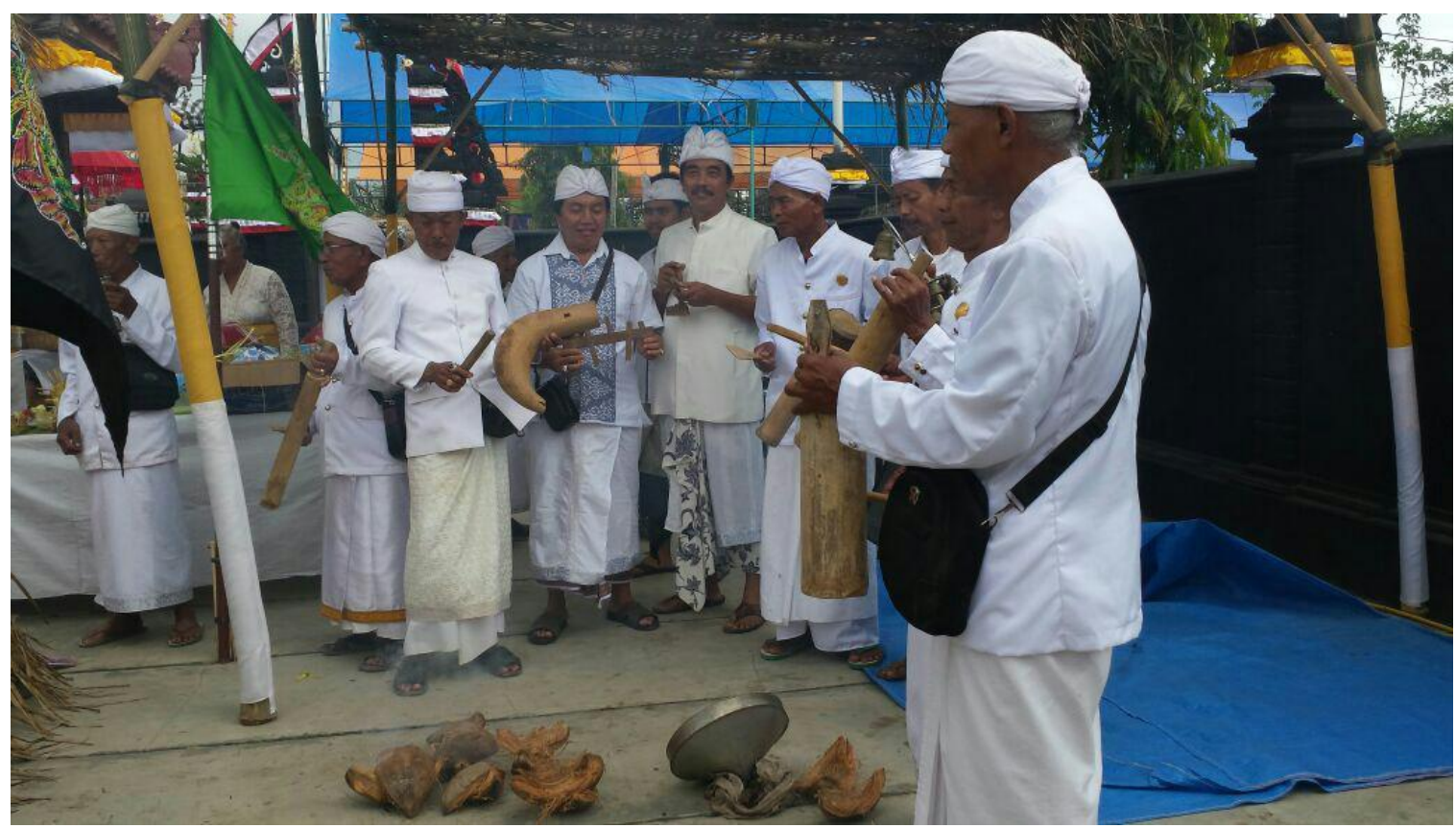

Gambar 7. Bakti Sosial Ikut Ngaturang Ayah Prosesi Upacara Pura Puja Dewata

Di Dusun Silirkrombang Desa Seneporejo Kecamatan Siliragung Kabupaten Banyuwangi Jawa Timur (Sumber: Observasi, Oktober 2017) 


\section{KESIMPULAN DAN SARAN}

Kesimpulan yang dapat diambil melalui kegiatan pengabdian 'Layanan Bantuan Teknis dan Bakti Sosial di Dusun Silirkrombang Desa Seneporejo Kecamatan Siliragung Kabupaten Banyuwangi Jawa Timur', adalah bahwa pola pendekatan partisipatif pada suatu kegiatan, tidak hanya akan dapat memberikan hasil yang lebih maksimal serta sesuai dengan aspirasi masyarakat, namun dapat memberikan jaminan keberlanjutan kegiatan/program bahkan pengembangannya pada waktu-waktu yang akan datang.

Model kegiatan yang dilaksanakan pada hibah ini tidak hanya telah dapat memberikan dampak nyata penataan dan pengembangan lingkungan binaan, namun telah dapat meningkatkan efesiensi dari sisi biaya dan juga waktu dari suatu kegiatan perencanaan serupa.

Kegiatan pengabdian seperti yang dilaksanakan pada hibah ini memungkinkan untuk dikombinasikan dengan kegiatan penelitian berupa dokumentasi sehingga kekayaan dan keunikan budaya khususnya karya arsitektur yang ada dan berkembang di masyarakat dapat terdata dengan baik serta dapat semakin memperkaya khasanah pengetahuan terkait.

\section{UCAPAN TERIMAKASIH}

Penghargaan yang setinggi-tngginya kepada masyarakat pengempon pura dan seluruh masyarakat Di Dusun Silirkrombang Desa Seneporejo Kecamatan Siliragung Kabupaten Banyuwangi Jawa Timur, yang telah memeberikan kesempatan untuk berpartisipasi. Kepada Rektor Universitas Udayana dengan seluruh jajarannya yang telah memberikan dukungan dan bantuan dana untuk melaksanakan Pengabdian Institusi ini. Serta rekan-rekan tim pengabdi yang telah bekerja keras untuk menyelesaikan tugas dengan baik.

\section{DAFTAR PUSTAKA}

Gelebet, I Nyoman, dkk, 1985, Arsitektur Tradisional Bali- Proyek Inventarisasi dan Dokumentasi Kebudayaan Daerah, Departemen Pendidikan dan Kebudayaan, Ditektorat Jenderal Kebudayaan Direktorat Sejarah dan Nilai Tradisional, Denpasar

Patra, Made Susila, 1992, Hubungan Seni Bangunan dengan Hiasan dalam Rumah Tinggal Adati Bali, Penerbit Balai Pustaka, Jakarta

Pulasari, Jro Mangku, 2007, Cakepan Asta Kosala-Kosali, Penerbit dan Percetakan Paramita, Surabaya

Pulasari, Jro Mangku, 2008, Cakepan Asta Kosala-Kosali lanAsta Bumi, Penerbit dan Percetakan Paramita, Surabaya

Tonjaya, Bandesa K., 1982, Asta Kosali, Penerbit dan Toko Buku Ria, Denpasar

Widana, Ida Bagus Gede, 2011, Dharmaning Hasta Kosali - Arsitektur Tradisional Bali, Penerbit Dharma Pura, Denpasar. 